\title{
STUDY OF IMPACT OF SEED BORNE FUNGAL PATHOGEN ON SEED GERMINATION, SEEDLING BIOMASS AND CHLOROPHYLL CONTENTS OF FOUR DIFFERENT PULSE CROPS
}

\author{
NIVEDITA SAURABH ${ }^{\mathrm{a} 1}$ AND N.K. SINGH ${ }^{\mathrm{b}}$
}

${ }^{a b}$ Department of Botany, K.R. College, Gopalganj, J.P. University, Chapra, Bihar, India

\begin{abstract}
Different saprophytic fungi causes damage to seeds in storage. Aspergillus flavus was isolated from the seeds of horse gram, cow pea, green gram, black gram and red gram kept in the stores of farmers. The pathogen was maintained in the laboratory. Seeds of aforesaid pulse crops were purchased from the standard seed merchant. In vitro inoculation was done and seeds were cultivated in pre-sterilized soil kept in earthen pots. It was observed that percentage of inhibition of germination was maximum in horse gram 37.12 and minimum in green gram 23.80. Reduction in biomass of seedlings was highest in black gram $54.51 \%$ while it was minimum in horse gram $\mathbf{5 2 . 4 8 \%}$. The chlorophyll- a, b and total chlorophyll contents were also influenced. Maximum reduction in chlo-a content $57.14 \%$ was found in green gram, while minimum reduction in chlo-a $\mathbf{2 0 . 0 0 \%}$ was found in cow pea. Similarly, highest percentage of reduction in chlo-b was found in case of Red gram $9.09 \%$ whiles the minimum $4.35 \%$ in black gram. Total chlorophyll contents were also observed. It was maximum in green gram 8.88\% while minimum in black gram 4.25. It was further noted that, there was reduction in all the parameter considered for study in the present work. All these indicated that the pathogen had negative impact on the seed germination, seedling biomass and the chlorophyll contents, when it was inoculated in the healthy seeds of different pulse crops as mentioned above.
\end{abstract}

KEYWORDS: Aspergillus flavus, Seed Borne, Seedling Biomass, Seed Germination, Chlo-a and b, Negative Impact

From the survey of literatures, it was noted that there are numerous fungal species, which are found on storage seeds and cause damage to the seeds. The degradation may be qualitative that caused degradation in the nutritional values of the seeds on which they are found. In the present study seeds of most commonly used pulses were used for the study of the impact of the saprophytic fungus. Pulses are the second most important group of food crops, belonging to family Leguminaceae. They form an important and indispensable part of our daily diet. It is an important source of dietary carbohydrates, proteins, essential amino acids and micronutrients such as calcium, phosphorus and iron (Kandhare, 2015). In the present study, most commonly used pulses such as horse gram, cow pea, green gram, black gram and red gram were selected to observed the impact of Aspergillus flavus on percentage of seed germination, seedling biomass and chlorophyll contents among the seedlings obtained from the contaminated seeds.

There are several reports related with mycoflora, associates with seeds of pulses, vegetables and cereals. Some of them may be cited here. Christensen, (1965) reported deterioration of stored grains by saprophytic fungi. Vijaya and Karan (1981) reported deterioration of cowpea seeds in storage by Aspergillus flavus. Sinha and Prasad (1981) observed effect of fungal metabolites on seed germination and seedling growth of Mung. Thakur and Prasad (1983) observed effect of fungal metabolite on seed germination and seedling vigor of Triticum vulgare. Kumar and Singh (1983) reported seed borne fungi of
Urad bean. Kumar and Patnaik (1985) reported seed borne fungus Alternaria alternata on pigeon pea. Singh and Prasad (1988) reported impact of seed mycoflora on seed quality and germination of Helianthus annuus. Patil et al; (1990) reported seed borne fungi on green gram.

Hashmi and Thrane (1990) isolated Fusarium spp. from different seeds and observed impact of mycotoxins and other secondary metabolites. Shankar and Rao, 1995 also reported impact of culture filtrates of selected mycoflora on seed germination and seedling growth. Kumar and Singh (2001) reported fungi causing seeds and seedling diseases in pigeon pea. Singh et al; (2004) observed pathogenic potential and control of seed mycoflora of ground nut. Arshad et al; (2005), Singh et al; (2005); Embaby et al; (2006); Arshad et al; (2006); Mali et al; (2008); Abdullah and Abdalall (2008); Mallesh et al; (2008); Charjan et al; (2010); Kayata and Agarwal (2010); Dumbrel et al; (2011); Singh et al; (2011); Singh et al; (2011); Patil et al; (2012); Ismile et al; (2012); Gangokar and Ayodhya (2013); Zakaria et al; (2014); Sadhu (2014); Chilkarni and Giri (2014); Irshad et al; (2015); Patekar et al; (2017); Khandhare (2019) all have reported seed borne fungi of different crops, including pulses, vegetables, cereals etc. In addition there are report regarding impact of seed borne fungi on seed germination, growth and biomass of different crops.

\section{MATERIALS AND METHODS}

These seed samples of each of five commonly grown pulses such as, horse gram, cow pea, green gram, black gram and red gram were purchased from the 
authorized seed traders of Hajipur, District Vaishali (Bihar). Ten seeds of each sample of test species were placed in pre-sterilized Petri plates lined with three wellmoistened blotting papers. Each treatment was replicated thrice. The Petri plates were incubated at $26 \pm 1^{\circ} \mathrm{C}$ for seven days. Fungal growth was observed. They were isolated and identified. Here most abundant species which was identified as Aspergillus flavus, was cultured on Potato Dextrose Agar Medium. This was maintained in the laboratory by frequent sub culturing on the same medium.

To observe the impact of Aspergillus flavus on percentage of seed germination, seedling biomass and chlorophyll contents, fresh seeds of above pulse crops were used. First of all these seeds were washed properly in running tap water and then surface sterilization was done with $0.1 \% \mathrm{HgCl}_{2}$ for 2-3 min. Above seeds were taken out and rinsed thrice with pre-sterilized distilled water. Water adhering on the surface of the seeds was removed with the help of pre-sterilized and dried tissue paper. Above seeds were placed in a well cleaned $250 \mathrm{ml}$ conical flasks separately. In the mean time spore suspension was prepared by harvesting spores from 10 days old culture of Aspergillus flavus. By serial dilution with sterilized distilled water, the number of spores $/ \mathrm{ml}$ suspension was adjusted to $1 \times 10^{5}$. This was done after counting the spores in $1 \mathrm{ml}$ suspension of spore from the stock suspension. For treatment $0.5 \mathrm{ml}$ of spore suspension was used for $5 \mathrm{~g}$ of seeds. The flasks were shaken manually for uniform contact of surface of the seeds with the spores. Above seeds were sown in the presterilized soil which was placed into earthen pots. These seeds were placed in the soil at the depth of nearly $5 \mathrm{~mm}$ to $10 \mathrm{~mm}$. Soil surface of the pots were covered with presterilized thin layer of cotton wool. All the pots were placed on the roof of the laboratory in natural condition. Observation was made on alternate day to observe the seed germination in the pots.

\section{Percentage of germination was calculated as}

$\%$ germination $=$ No. of germinating seeds $/$ Total no. of seeds sown $X 100$

At least10 seedlings were allowed to growth per pots. These pots were kept moistened by spraying presterilized tap water on every alternate day. The seedlings grew vigorously. New leaves were formed. After 4 weeks the biomass of the seedlings was determined.

\section{Determination of Biomass}

The pots were moistened with pre-sterilized distilled water and seedlings were carefully uprooted so that no part of the root should be left in the soil. They were carefully washed with tap water to remove the soil particles. A set of three seedlings in three replicates form each lot were kept in butter paper pocket and dried in an incubator at $60^{\circ} \mathrm{C}$ for 48 hours. It was placed in desiccators containing $\mathrm{CaCl}_{2}$ for next 48 hours. The weight was taken. The weight of per seedling in mg was taken. In this way biomass was calculated and the mean of the data was placed in table-2 for discussion.

\section{Determination of Chlorophylls}

Cotyledonary leaves form 15 days old seedlings were collected in a clean polybag. These leaves were washed under running tap water and were dried with well sterilized tissue paper. The petiole and mid ribs were carefully removed with the help of a sterile blade. Now $150 \mathrm{mg}$ of the leaflets was weighed and chlorophyll was extracted. Leaves were homogenized in $15 \mathrm{ml}$ acetone $(80 \%)$ in the mortar with the help of pestle. Extract was filtered through muslin cloth and the residue was used for extraction again. This was repeated thrice and the extracts were pooled together and centrifuged at $5000 \mathrm{rpm}$ for 15 min. the supernatant was taken and used for the determination of OD. The OD was determined at $645 \mathrm{~nm}$ and $663 \mathrm{~nm}$ with the help of UV Spectrophotometer. The amount of chlorophyll-a mg/g fresh weight of leaves was calculated by the formula proposed by Wiltham et al; 1971.

Total chlo-a $(\mathrm{mg} / \mathrm{g}$ fresh weight $)=[12.7(\mathrm{D663})$ 2.69(D645) X V/1000XW

Chlo-b $(\mathrm{mg} / \mathrm{g}$ fresh weight $)=[22.9(\mathrm{D645})-4.68(\mathrm{D663})$ X V/1000XW

Total Chlo-a + Chlob $=[20.2(D 645)+8.02(D 663) X$ V/1000XW

Where $\mathrm{V}=$ Volume of extract in $\mathrm{ml}$.

$\mathrm{W}=$ Fresh weight of the leaves $\mathrm{g}$

$\mathrm{D}=$ Density at noted wavelength

\section{Determination of Chlorophylls Contents}

Data for Chlo-a, Chlo-b and total chlorophylls were placed in table-3 for analysis.

For the determination of percentage of seed germination, biomass of seedlings and chlorophylls contents, the healthy seeds of all the five pulse crops were shown as control. These data have been also placed in respective tables- such as Talbe- 1 , Table- 2 and Table- 3 .

\section{RESULTS AND DISCUSSION}

Calculation of germination percentages of five different pulses on $15^{\text {th }}$ day of showing after artificial inoculation was done.

Seed germination test was followed for seedling biomass as indicate by the dry weights and chlorophyll contents of the above seedling. From the table-1, it was noted that percentage of germination in the control ranged between 68.10 to 75.20 . The highest percentage of germination was found in case of red gram 75.20 while the minimum in case of black gram that was 68.10. Similarly, percentage of germination among the 
inoculated seeds ranged between 44.10 to 56.70 . Here green gram had $56.70 \%$ germination and Black gram $44.10 \%$. Here the percentage of inhibition of germination due to inoculation of the fungal spores was maximum in case of horse gram which was 37.13 and minimum 23.80 in case of green gram. The discrepancy in the percentage of inhibition may be due to the seed structure and its composition. Impact of fungal metabolites on seed germination and seedling growth of Mung has been reported by Singh and Prasad (1981); Thakur and Prasad (1983) in case of Triticum vulgare; Singh \& Prasad (1988); Sharma and Rao (1995) in case of gram seeds, Debnath et al; (2012) in case of maize seeds, Patil et al; (2012) in case of some pulses. Khokhar et al; (2013) in case of wheat seeds, Gauruba et al; (2014) in cse of maize seeds. Khandare (2015) in case of chick-pea. All these workers have concluded that there were considerable reductions in the percentage of germination of seeds of different plants when treated with culture filtrates of the fungi, isolated from the respective seeds. Findings of the present work therefore, corroborate with the findings of the above workers.

Biomass of seedlings raised form the seeds inoculated with fungal spores was also determined. Mean of the data was placed in table-2. Here also we get discrepancy in the biomass as expressed in $\mathrm{mg} /$ dry weight was found in the healthy and treated seedlings. The percentage loss in biomass among the treated seedlings in comparison to control was noted. Maximum percentage of loss 54.51 was found in Black gram and minimum 52.48 in case of horse gram.

The loss in biomass may be due to the action of the secondary metabolites of the fungus, which reduces different biochemical reactions in the inoculated seedlings. Impact of culture filtrates and mycotoxins on seedling vigor has been reported by different workers. Thakur and Prasad (1983) observed impact of fungal metabolites on seed germination and seedling vigor of Triticum vulgare. Shankar and Rao (1995) observed the impact of culture filtrates of selected seed mycoflora on seedling vigor of pulses. Domijan et al; (2005) observed impact of ochratoxin on dry bean, for germination and seedling growth. Khayum et al; (2006) observed effect of seed mycoflora of Soybean on seedlings growth characters. Mallesh et al; (2008) observed impact of seed mycoflora on seed germination and seedling vigour in case of Pigeon pea. Jalander and Gachande (2012) observed impact of soil fungi on seed germination and seedling growth of some pulses and cereals. Mogle and Maskg (2012) also reported impact of seed mycoflora on seed germination and seedling vigor index of cowpea. Chaudhary et al; (2018) observed effect of seed mycoflora in case of Mung bean, on seed germination and seedling vigor. Wani and Alum (2018) reported effect of seed borne fungi on seed germination and seedling vigour of pea seeds. All these findings are in agreement with the finding of present work as here also there was reduction in biomass of the seedlings raised form the inoculated seeds with fungal spores.

Chlorophyll contents of the seedlings raised from seeds treated with fungal spores were also determined. Form the table-3, it may be observed that remarkable reductions in Chlo-a, Chlo-b and total chlorophyll contents were found among the seedlings which were treated than that of the control. Maximum loss in chlo-a of green gram seedling was $57.14 \%$ while in chlo-b it was in red gram (9.09\%). Similar was the case for total chlorophyll contents. Here maximum loss was in case of green gram, where the loss was $8.88 \%$. Loss in chlorophylls of different pulses showing discrepancy may be due to leaf structure and chlorophyll contents.

Loss in chlorophyll contents of different plants, where seeds were infested with fungal pathogens have been reported by Al-Askar et al; (2013); Ahmad and Jutta (2015) and Ahmad and Zaidi (2018). These workers have concluded that seed borne mycoflora also include toxigenic strains. These pathogens may produce phytotoxins that may disturb the synthesis of chlorophyll pigments or may degrade the synthesized pigments. Due to this there are reductions in total chlorophyll contents among the seedlings of infected seeds. In the present study seeds were inoculated with Aspergillus flavus and there is reduction in the chlorophylls contents of the inoculated seedlings in comparison of the healthy seeds. Therefore, findings of the present work are in agreement with the aforesaid workers.

Table 1: Showing impact of Aspergillus flavus on percentage of seed germination of aforesaid seeds of pulse crops

\begin{tabular}{|c|c|c|c|c|}
\hline S.N. & Name of the crop & C & I & \% inhibition \\
\hline 1 & Horse gram & $70.30 \pm 0.02$ & $44.20 \pm 0.04$ & 37.13 \\
\hline 2 & Cow pea & $72.20 \pm 0.06$ & $48.60 \pm 0.06$ & 32.69 \\
\hline 3 & Green gram & $74.40 \pm 0.08$ & $56.70 \pm 0.04$ & 23.80 \\
\hline 4 & Black gram & $68.10 \pm 0.04$ & $44.10 \pm 0.02$ & 32.24 \\
\hline 5 & Red gram & $75.20 \pm 0.04$ & $50.40 \pm 0.08$ & 32.98 \\
\hline
\end{tabular}


Table 2: Biomass of seedlings raised form the seeds inoculated with the spores of Aspergillus flavus of different pulse crops

\begin{tabular}{|c|c|c|c|c|}
\hline \multicolumn{5}{|c|}{ Expressed as mg/ seedling. Mean dry weights+ SE } \\
\hline S.N. & Name of the crops & Control & Inoculated & \% loss in biomass \\
\hline 1 & Horse gram & $28.20 \pm 0.04$ & $13.40 \pm 0.08$ & 52.48 \\
\hline 2 & Cow pea & $23.40 \pm 0.08$ & $11.10 \pm 0.02$ & 52.56 \\
\hline 3 & Green gram & $30.60 \pm 0.06$ & $14.20 \pm 0.04$ & 53.60 \\
\hline 4 & Black gram & $27.70 \pm 0.04$ & $12.60 \pm 0.06$ & 54.51 \\
\hline 5 & Red gram & $28.10 \pm 0.02$ & $13.20 \pm 0.04$ & 53.02 \\
\hline
\end{tabular}

Table 3: Chlorophyll contents of seedlings raised from treated seeds of the pulse crops with spore suspension of Aspergillus flavus. (Chlorophyll expressed in $\mathrm{mg} / \mathrm{g}$ of leaves)

\begin{tabular}{|c|c|c|c|c|c|c|}
\hline $\begin{array}{c}\text { Name of } \\
\text { Pulse Crop }\end{array}$ & Chlorophyll-a & & $\%$ loss & Chlorophyll-b & & $\%$ loss \\
\hline & $\mathrm{C}$ & I & & $\mathrm{C}$ & I & \\
\hline Horse gram & $0.07 \pm 0.004$ & $0.05 \pm 0.033$ & 28.57 & $0.44 \pm 0.004$ & $0.42 \pm 0.008$ & 4.55 \\
\hline Cow pea & $0.05 \pm 0.003$ & $0.04 \pm 0.003$ & 20.00 & $0.42 \pm 0.005$ & $0.40 \pm 0.006$ & 4.76 \\
\hline Green gram & $0.07 \pm 0.003$ & $0.03 \pm 0.002$ & 57.14 & $0.43 \pm 0.006$ & $0.40 \pm 0.006$ & 6.25 \\
\hline Black gram & $0.07 \pm 0.004$ & $0.05 \pm 0.003$ & 28.57 & $0.46 \pm 0.008$ & $0.44 \pm 0.004$ & 4.35 \\
\hline \multirow[t]{2}{*}{ Red gram } & $0.05 \pm 0.002$ & $0.03 \pm 0.002$ & 40.00 & $0.44 \pm 0.006$ & $0.40 \pm 0.006$ & 9.09 \\
\hline & \multicolumn{6}{|c|}{ Percentage loss in total chlorophylls } \\
\hline Species & \multicolumn{3}{|c|}{ Control } & \multicolumn{2}{|c|}{ Inoculated } & $\%$ loss \\
\hline Horse gram & \multicolumn{3}{|c|}{$0.46 \pm 0.004$} & \multicolumn{2}{|c|}{$0.43 \pm 0.008$} & 6.52 \\
\hline Cow pea & \multicolumn{3}{|c|}{$0.44 \pm 0.006$} & \multicolumn{2}{|c|}{$0.41 \pm 0.006$} & 6.81 \\
\hline Green gram & \multicolumn{3}{|c|}{$0.45 \pm 0.004$} & \multicolumn{2}{|c|}{$0.41 \pm 0.004$} & 8.88 \\
\hline Black gram & \multicolumn{3}{|c|}{$0.47 \pm 0.008$} & \multicolumn{2}{|c|}{$0.45 \pm 0.004$} & 4.25 \\
\hline Red gram & \multicolumn{3}{|c|}{$0.42 \pm 0.006$} & \multicolumn{2}{|c|}{$0.41 \pm 0.006$} & 2.38 \\
\hline
\end{tabular}

\section{CONCLUSION}

Seed borne mycoflora on the stored seeds of different crops, reduces, germination, seedling growth and chlorophyll contents. All these are important factors for loss in yield. Therefore, seeds which are stored without treatment should not be used for cultivation.

\section{ACKNOWLEDGEMENT}

The authors are thankful to the Principal, K.R. College, Gopalganj for providing laboratory and library facilities for the present research work.

\section{REFERENCES}

Abdullah A.M. and Al Abdalall, 2008. Pathological studies of fungi associated with pulse seeds during storage in Dammam Province, Kingdome of Saudi Arabia. Middle Eastern and Russian Journal of Plant Science and Biotechnology

Ahmad L. and Razi K.Z., 2018. Effect of chemical and biological treatment for the control of seed borne mycoflora of Barley. Aeta Scientific Agriculture, 2(6): 06-11.

Ahmed A. Ismaiel and Jutta P., 2015. Mycotoxin producing fungi and mechanism of phytotoxicity. Agriculture, 5(3): 492-537.

Al-Askar A.A., Ghoneem K.M. and Rashad Y.M., 2013. Management of some seed borne pathogens attacking alfalfa plants in Saudi Arabia. African J. of Microbiol. Res., 7(4): 1197-1206.

Arshad J., Bajwa R., Javaid A. and Anjum T., 2005. Fungi associated with seeds of pulses collected from Lahore and their effect on seed germination. Mycopath., 3(1\&2): 13-16.

Bhghbani F., Lotti R. and Kalaji M.M., 2019. Impact of Fusarium verticilloides on chlorophyll fluorescence parameters of two maize lens. European J. of Plant Pathology, 154: 337-346.

Charjan S.U., Patil A.E. and Udasi R.N., 2010. Seed quality and mycoflora associated with bold and 
wrinkled seeds of cow pea. J. Phytol. Res., 23(2): $379-380$.

Chaudhari, R.I., Vikram R.G. and Mandaviya, T.K., 2018. Effect of seed mycoflora on Mung bean seed health with respect to seed germination and seedling vigor. Int. J. Curr. Microbiol. App. Sci., 7(7): 1967-1976.

Chilkuri A. and Giri G.K., 2014. Detection and transmission of seed borne mycoflora in green gram and effect of different fungicides. Int. Journal of Advanced Res., 5(5): 1182-1186.

Clristensen C.M., 1965. Deterioration of stored grain by fungi. Ann. Rev. Phytopath., 3: 69-84.

Debnath M., Sultan A. and Rashid A.Q.M.B., 2012. Effect of seed borne fungi on the germinating seeds and their biocontrol in maize. J. Environ. Sci. and Natural Resources, 5(1): 117-120.

Domijan A.M., Peracia M., Zlender V., Cvjetkovic B., Jurjevic Z., Topolovel P.S. and Ivic D., 2005. Seed borne fungi and ochratoxin, $\mathrm{A}$. contamination of dry beans (Phaseolus vulgaris L.) in the Republic of Crotia. Food and Chemical Toxicology, 43(3): 427-432.

Dumbrel S., Guldekar D. and Potdukar S.R., 2011. Survey of seed borne fungi on onion (Allium сера) from various locations of Maharashtra. J. Soil Crops, 21(2): 221-224.

Embaby E.M., Mona M. and Galib A., 2006. Seed borne fungi and mycotoxins associated with some legume seeds in Egypt. J. Applied Sciences Res., 2(11): 1064-1071.

Gangaokar M.N. and Ayodhya K.D., 2013. Study of seed borne fungi on different legumes. Trends in Life Science, 2(1): 112-116.

Garuba T., Abdulrahman A.A., Olahan G.S., Abdulkareem K. and Amadi J.E., 2014. Effect of fungal filtrates on seed germination and leaf anatomy of maize seedlings (Zea mays L., Poaceae). J. Appl. Sci. Environ. Manage, 18(4): 662-667.

Hashmi M.H. and Thrane U., 1990. Mycotoxins and other secondary metabolites in species of Fusarium isolates from seeds of Capsicum, Coriandrum and Fenugreek. Pak. J. Bot., 22: 106-116.

Irshad G., Haider Z. and Bushra S., 2015. Study on mycoflora associated with seeds of different citrus species. Int. J. Adv. Biol., 2(2): 1-14.

Ismile M., Anwar S.A., Ul-Haque M.I., Iqbal A., Ahmad N. and Arian M.A., 2012. Seed borne, fungi associated with cauliflower seeds and their role in seed germination. Pakistan J. Phytopathol., 24(1): 26-31.

Jalander V. and Gachande B.D., 2012. Effect of fungal metabolites of some rhizosphere soil fungi on seed germination and seedling growth of some pulses and cereals. Science Res. Reporter, 2(3): 265-267.

Kayata, Renu and Agarwal R.D., 2010. Isolation of seed surface fungi of Lens culinaris. J. Phytol. Res., 23(2): 335-337.

Khandare A.S., 2015. Toxic effects of seed borne fungi on seed health of Chick pea. Int. J. Innov. Sci. Engin. And Technol., 2(1): 238-240.

Khandhare A.S., 2019. Pathogenic variations in seed borne fungi of pulses. J. of Agriculture and Aqua Culture, 1(2): 01-16.

Khayum A.S., Anandam R.J., Prasad B.G., Munikrishnaiah M. and Gopal K., 2006. Studies on seed mycoflora of soybean and its effect on seed and seedling quality characters. Legume Res., 29(3): 186-190.

Khokhar I., Haider M.S., Mukhtar I., Ali A., Mustaq S. and Asfaq M., 2013. Effect of Penicillium species culture filtrate on seedling growth of wheat. Mycologia, 3(1): 24-29.

Kumar S., 2014. Plant disease management in India: Advances and managements. African Journal of Agricultural Res., 9(5): 1207-1217.

Kumar D. and Singh T., 2001. Fungi causing seed and seedling disease in pigeon pea. Journal Phytopathology Res., 14(1): 39-42.

Kumar K. and Patnaik P., 1985. Seed borne nature of Alternaria alternata in pigeon pea, detection and control. Indian J. Plant Pathol., 3(1): 69-73.

Kumar K. and Singh J., 1983. Seed borne fungi of Urad bean, Vigna mungo $\mathrm{L}$ their significance and control. Indian J. Plant Pathol., 2: 178-181.

Kumari V. and Karan D., 1981. Deterioration of cow pea seeds in storage by Aspergillus flavus. Indian Phytopath., 34(2): 222-223.

Mali V.P., Jamdhade V.M. and Patale S.S., 2008. Studies on seed mycoflora of green gram and black gram. Bionano Frontier, 1(2): 16-20.

Mallesh S.B., Deshpande V.K. and Kulkarni S.A., 2008. Effect of seed mycoflora management on seed germination and seedling vigor of pigeon pea during storage. J. Ecobiol., 23(1): 77-82.

Mogle U.P. and Maske S.R., 2012. Efficacy of bioagents and fungicides on seed mycoflora, germination 
and vigour index of Cowpea. Science Res. Reporter, 2(3): 321-326.

Patekar M.A., Kadam R.M. and Biradar R.P., 2017. Assessment of seed borne fungi of tomato, and brinjal seeds. Trends in Biotechnology Research, 6(1): 13-19.

Patil D.P, Pawar P.V. and Muley S.M., 2012. Mycoflora associated with pigeon pea and chick pea. Int. Multidisciplinary Res. Journal, 2(6): 10-12.

Patil D.P., Muley S.M. and Pawar P.V., 2012. Impact of fungal culture filtrate (Mycotoxins) on seed germination of some pulses. World J. Science and Technology, 2(8): 01-02.

Patil S.D., Memane S.A. and Konde B.K., 1990. Occurrence of seed borne fungi of green gram. J. of Maharashra Agric. Univ., 15(1):44-45.

Sadhu K.A., 2014. Seed borne fungi and their effect on seed health of green gram. Bioscience Discovery, 5(2): 251-255.

Shankar V. and Rao C.G.P., 1995. Effect of culture filtrates of some selected seed mycoflora of green gram on seed germination and seedling growth. J. Ecobiology, 7(3): 225-230.

Singh A.K., Srivastva J.N. and Shukla D.N., 2011. Evaluation of seed mycoflora of pigeon pea and their fungicidal management. J Mycopathol. Res., 49(2): 313-316.

Singh K., Singh K., Singh A.K. and Singh R.P., 2005. Detection of seed mycoflora of Chick-pea (Cicer arietinum L.). Annals of Plant. Protection Sci., 13(1): 167-171.
Singh S., Kaur I., Sirari A. and Singh N., 2011. Chemical and biological management of seed borne infection of Botrytis cinera in Chickpea. Pl. Dis. Res., 26(2): 143-144.

Singh S.D., Rawal P. and Bhargava N.K., 2004. Pathogenic potential and control of seed mycoflora of ground nut (Arachys hypogaea). J. Mycol. Pl. Pathol., 34(2): 687-690.

Singh B.K. and Prasad T., 1988. Effect of seed quality on germination and seed mycoflora in Sun flower (Helianthus annuus). J. Indian Bot. Soc., 67: 316-317.

Sinha M.K. and Prasad T., 1981. Effect of fungal metabolites on seed germination microbial association and seedling growth of Mung. Indian Phytopath., 34(4): 515-517.

Swami C.S. and Alane S.K., 2013. Efficacy of some Botanicals against, seed borne fungi of green gram (Phaseolus aureus Roxb.). Bioscience Discovery, 4(1): 107-110.

Thakur M.K. and Prasad R.B., 1983. Effect of fungal metabolites on seed germination and seedling vigour of Triticum vulgare var. Shera. Geobios., 10: $91-92$.

Wani I.A. and Arun K., 2018. Effect of seed germination and seedling vigour by seed borne fungi of pea (Pisum sativum L.). Int. J. of Advance Res. in Science \& Engineering, 7(4): 186-191.

Zakaria L., Soh W.K. and Yee T.L., 2014. Diversity of fungi isolated from vegetable seeds. Malaysian J. Microbiol., 10(3): 155-160. 